\title{
QUINE'S PHILOSOPHY OF LOGIC AND MATHEMATICS
}

The last four words of my title may seem redundant, since virtually all Quine's philosophical writings, early and late, pertain directly or indirectly to logic, mathematics, or both. My aim here will in fact be less ambitious and more realistic than my title would thus suggest. I will be concerned not with anything and everything that Quine has had to say as a philosopher and logician about logic and mathematics, but more specifically with Quine's struggles as an avowed empiricist with the two main problems that logic and mathematics have traditionally posed for any philosophy that takes senseexperience to be the primary source of knowledge: first, the appearance that logical and mathematical knowledge are a priori or independent of any reliance on sense-experience; second, the appearance that the objects of mathematical knowledge are abstract and beyond the realm of senseexperience. I will take up the two issues in the order listed.

Quine's views on both were in large part developed in reaction to logical positivism, the dominant form of empiricism in the early years of his career, and more specifically in reaction to the views of Carnap, whom Quine avers to have been the greatest influence on his philosophical thought. This makes “Carnap on Logical Truth" (1960) and "On Carnap's Views on 
Ontology" (1951) key Quinean texts on a priori knowledge and on abstract objects, respectively. Other key texts on a priori knowledge are "Truth by Convention" (1936), Quine's most important early philosophical paper, and “Two Dogmas of Empiricism” (1951), Quine's most famous paper of all, as well as the comparatively late "Epistemology Naturalized" (1971). Other key texts on abstract objects are "On What There Is" (1948) and "Posits and Reality" (1960), as well as the notorious joint paper with Goodman, "Steps toward a Constructive Nominalism" (1947), which takes a position at variance with the main line of Quine's writings on the issue.

\section{$\S 1 \quad$ A Priori Knowledge: Kant to Carnap}

Quine opens "Carnap and Logical Truth" with a mention of Kant, and it will be well to begin here also with Kant and his grappling with the problem of modality. The mystery of modality, the category to which necessity and possibility belong, is how we can have knowledge of it: To paraphrase the First Critique (B3), sense-experience may be able to teach us that some things are so and others are not, but seems unable by itself to teach us that some of the things that are not only are but had to have been, while others need not have been but just happen to be, or that some of the things that aren't might well have been but just happen not to be, while others not 
only aren't but could not have been. Kant concludes that knowledge of necessity must be a priori, and indeed virtually identifies what is known to be necessary with what is known a priori, from which conclusion it is but a short step, taken by many of Kant's successors, to outright identification of the necessary with what is knowable a priori. Thus the mystery of modality reduces, for Kant and many of his successors, to the question of how a priori knowledge is possible.

Kant himself took one kind of a priori knowledge, that represented by what he called analytic as opposed to synthetic judgments, to be unmysterious. And so for him the mystery takes the more specific form of the question how synthetic a priori knowledge is possible. By contrast, the positivists rejected Kant's claims of "synthetic a priori” knowledge, reclassifying all of Kant's supposed examples. They were therefore left with "only" the question of how analytic knowledge is possible.

Kant's premier examples of the synthetic a priori had been provided by mathematics, both arithmetic and geometry. The positivists reclassified geometry, insofar as it is thought of as being about the physical space, as a posteriori, and reclassified arithmetic as analytic. Behind the positivists' reclassification of geometry as a posteriori stands the influence of nonEuclidean geometry since Gauss, and especially of the relativity theory of 
Einstein; behind their reclassification of arithmetic as analytic stands the influence of the logicism of Frege and Russell.

The reducibility of arithmetic through suitable definitions to logic, and consequent analyticity of arithmetic, was Frege's chief philosophical claim, and he made the project of establishing it his lifework. Frege's program broke down in paradox, but was taken up in revised form by Russell, joined by Whitehead, coauthor with him of the monumental Principia Mathematica. (In the autobiographical sketch "My Mental Development," Russell describes this work of his as "a parenthesis in the refutation of Kant.") The logicist position later won the allegiance of Carnap, who appeared as its spokesman (as a last-minute replacement for the recentlydeceased Ramsey) at the famous 1930 Erkenntnis symposium on the foundations of mathematics in Königsberg.

Carnap's understanding of analyticity, however, differed from that of Frege, let alone Kant, and his revised conception of analyticity carried with it a proposed answer to the question of how analytic knowledge is possible. For Frege, analyticity meant reducibility to logic by definitions. Definitions presumably being true by virtue of the meanings of the words they involve, the result is that what is analytic is true by virtue of meaning plus whatever it is that logic is true by virtue of, a question Frege does not much discuss. For 
Carnap, logic itself is true by virtue of meaning, specifically, by virtue of the meanings of the logical particles. This Quine calls "the linguistic doctrine of logical truth." Assuming this doctrine, analyticity is simply truth by virtue of meaning, or as Carnap and like-minded philosophers sometimes preferred to say, by virtue of semantic rules or linguistic conventions.

On such a view, we are able to recognize analytic truths as true by employing rules or conventions we learned in the course of learning our native language, and in this way the mystery of modality is solved. By the time we get from Carnap and the original positivism of 1920s Vienna to Ayer and the popularization of positivism in 1930s Britain, we find the purported solution to the mystery of modality just indicated, the claim that logic and mathematics are true simply because we have adopted the convention of holding them true no matter what, being made independently of any commitment to the technical details of any logicist program for reducing mathematics to logic.

$\$ 2 \quad$ A Priori Knowledge: Quine vs Carnap

Quine was brought up in the logicist tradition. Whitehead was at least nominally his dissertation supervisor, and he has been quoted as saying of Principia Mathematica, "This is the book that has meant the most to me." 
Nonetheless, Quine could not accept the logicist claim that mathematics is reducible to logic. This, however, was mainly for reasons related to the existence assumptions of mathematics, a topic whose discussion I must postpone. But quite apart from any issues about existence, Quine objected to claims of truth by convention even as it applies to pure logic, let alone higher mathematics.

In "Truth by Convention," citing Lewis Carroll's well-known philosophical fable "What the Tortoise Said to Achilles," Quine poses the key dilemma for conventionalism. If one wants to claim that logic's truth is established by immediate conventions, the one faces the difficulty that there are infinitely many logical truths, while we can have adopted at most finitely many conventions. If one wants to claim that logic's truth follows mediately from conventions, then one faces the difficulty that logic is needed to infer logic from the conventions. Consider, for instance, the logical truth "Either $68+57=125$ or $68+57 \neq 125$." Surely the truth of this one very specific example is not itself a linguistic convention. But if one wants to claim that its truth follows from linguistic conventions, one faces the question: What kind of fact is it that the truth in question thus follows? Any fact about what follows from what would seem to be a necessary fact, an a priori fact, a logical fact; but if such facts are the product of linguistic convention, where 
is the linguistic convention from which this one follows? By what convention does "Either $68+57=125$ or $68+57 \neq 125$ " follow from the conventions from which it is supposed to follow? Pursuing such questions, one soon finds oneself involved in an infinite regress of the same kind as Achilles and the Tortoise in Carroll's tale.

Unfortunately, the insight of "Truth by Convention" never sank in as deeply as it should have, and the problem it presents has to this day been comparatively little discussed. (Kripke's Wittgenstein on Rules constitutes the most important treatment, though if the much-disputed exegetical claims of that work are correct, there is another and earlier one concealed in the cryptic paragraphs of the Philosophical Investigations.) The insight even to some extent fades from view in Quine's own later writings. For though the moral of Carroll's fable is that one must have rules as well as truths in logic, this point tends to be left further and further in the background in Quine's subsequent discussion of philosophy of logic, where he so often speaks of logic as if it were, like mathematics, simply a body of truths of a certain kind.

If Quine seldom emphasizes in his later writings the specific argument of "Truth by Convention," he does very much emphasize its conclusion, frequently reiterating his rejection of the notion that there are some truths 
that are true purely by convention, or in a word, that are analytic; and he very much emphasizes the more specific claim that logic and mathematics lack the incorrigibility or immunity from revision traditionally ascribed to the analytic and the a priori. But Quine's long polemic against the analytic/synthetic distinction, and the battery of later arguments he brings against the supposed distinction in "Two Dogmas of Empiricism" and elsewhere, will not be treated in detail here. I will just note a few points of clarification.

First, though Quine denies that mathematical and logical truths are a priori in any traditional sense implying unrevisability or incorrigibility, he does not hold, as Mill apparently did, that they are a posteriori in the sense of being simple inductive generalizations from empirical observations; it is only very general theoretical considerations about the organization of the whole body of our knowledge, and not the results of any one crucial experiment, that might lead to the adoption of a revised mathematics or logic. What Quine rejects is less the classification of mathematics and logic as a priori rather than a posteriori than the whole distinction between the two supposed kinds of knowledge.

Second, though Quine does indeed hold that if experience proves recalcitrant, and anomalies accumulate, and a scientific revolution seems 
called for, we may elect to change any part of our overall theory, even our mathematics or our logic, no part of our total theory being in principle immune to correction or revision, he does not in practice advocate any of the proposed deviant logics to be found in the literature, nor does he think it likely that any such proposal would ever be well-enough motivated to be worth adopting. For any revolution in mathematics and logic would involve disruptions in comparison with which the adoption of relativity theory and its new view of spacetime would seem a trivial change, and so a "maxim of minimum mutilation" militates against any logicomathematical revolution.

Third, though Quine will not say that logical truths are true by virtue of meaning, and indeed is skeptical about the very notion of meaning - and therewith of the notion of synonymy or sameness of meaning, and the notion of a correct or erroneous translation as one that does or does not preserve meaning or carry synonyms to synonyms, as contrasted with a notion of translations being merely better or worse for various interests and purposes - nonetheless something does remain of "the linguistic doctrine of logical truth" even for Quine. The remnant is especially to be seen in his discussion of deviant logics in his Philosophy of Logic. The only real-life example of serious, sustained, systematic use of a deviant or nonclassical logic is the use of intuitionistic logic among intuitionistic mathematicians. Though to a first 
approximation it may be said that intuitionistic and classical logic differ in that the latter accepts and the former rejects the law of the excluded middle, $p$ or not $p$, commentators generally agree that what the intuitionists rejects is not quite the same thing as what the classicists accepts, since "not" and "or" have different meanings for the two groups. As a skeptic about meaning, Quine is not willing to say quite this, but he is willing to say that there may be no very good translation from the intuitionist to the classical language or from the classical to the intuitionist. In this respect, the change from classical to intuitionistic logic is quite unlike the change involved in a trivial permutation of vocabulary, say using "and" for "or" and "all" for "some" and inversely. The remnant of the linguistic doctrine of logical truth in Quine is the claim that if we were to change our logic, very likely the change would make it difficult or impossible to translate our post-revolutionary language into our pre-revolutionary language, and vice versa. (He does not use Kuhn's term “incommensurable” in this connection.)

Fourth, though Quine in rejecting the analytic/synthetic distinction rejects the notion that there are some truths that are true purely by convention, he by no means rejects all talk of "convention." Our lore, Quine says at the end of "Carnap and Logical Truth," is a fabric black with fact and white with convention, and overall not just gray but pale gray, though there 
are in the fabric no wholly white threads. In the foreword to his student David Lewis's Convention, Quine spells out what talk of conventionality amounts to for him: "a certain indifference." Thus to say that our scientific theories are in large part conventional is to say that we could have done things differently in science in many ways and been no better or worse off for it. Conventionality in this sense Quine more usually called "underdetermination," and under that label it is a theme of much of his philosophy.

$\S 3$ Abstract Objects: The Scope of Logic and "Ontological Commitment" Let me return now to the topic, postponed earlier, of the distinction between logic and mathematics, and Quine's rejection of logicism. To begin with, Quine's conception of the limits of logic is in some ways quite traditional. Taking logical truths to be sentences, not propositions, he begins by classing a sentence as a logical truth if and only if every sentence of the same logical form is true. Here logical form is simply the skeleton of the sentence that is left when all words except the logical particles are replaced by schematic letters. (It turns out that, on Quine's view, one generally has to do a good bit of paraphrasing before logical form becomes apparent, and as a skeptic about meaning and synonymy, Quine is not in a position to claim 
that the paraphrasing involved preserves meaning or carries synonyms to synonyms; it is enough, for applications of logical analysis, that it should more or less obviously preserve truth values.) What is missing from, or rather, deliberately left out of, Quine's conception is any deep theoretical criterion for what counts as a logical particle and what doesn't. Quine simply contents himself with a list: not, and, or, if, all, some, understood in stylized or regimented ways, as they are understood in mathematics. This list gives us the whole of classical, extensional, first-order logic, the logic of the textbooks, and nothing more. Two kinds of potential extensions in particular are rejected.

First, Quine excludes from his list necessarily and possibly, which would take us beyond classical to modal logic. Presumably they might be admitted as well if the notions of necessity and possibility could be made adequate sense of; but by Quine's lights they cannot. Already C. I. Lewis, the founder of modern modal logic, and Carnap, against whose views Quine is reacting, set aside any more "metaphysical" notion of necessity than analyticity. Quine on the one hand rejects the notion analyticity, and on the other hand holds that even if one accepts it as he does not, one cannot make sense of quantified modal logic while interpreting necessity as analyticity, but rather would have to go back to a kind of "Aristotelian essentialism" that 
C. I. Lewis and Carnap would reject. But Quine's long polemic against any of the "Three Grades of Modal Involvement" he distinguishes in the paper of that title will not be gone into here. Other "intensional" operators are excluded along with the modalities of necessity and possibility.

Second, Quine also excludes all deviant forms of quantification, such as so-called branching quantification, or so-called substitutional quantification. Again, Quine's long polemic about quantification and the related issue of the existential implications of theories, which Quine insists on calling their "ontological commitments," will not be gone into here, except insofar as these matters bear directly on philosophy of mathematics and the status of the logicist thesis.

In this connection, what is crucial is that Quine will not count as "logic" so-called second-order logic, let alone so-called higher-order logic, also known as type theory. This suffers, in the first place, from being grammatically nonsensical. In even the simplest second-order formula “ $\exists F F$ " we find the same letter appearing once in a position (after " $\exists$ ") where only a noun or pronoun can go, and once in a position (before " $x$ ") where only a predicate can go. And the grammatical nonsense can encourage an illusion of getting something for nothing. Russell and Whitehead reduced mathematics to type theory, which Russell described as a "no classes" 
theory; but Quine denies that this was genuine reduction to pure logic, and in this sense rejects the logicist thesis. According to Quine, the variables quantified over in second- and higher-order logic must be interpreted ranging over as sets or classes, unless they are interpreted as ranging over properties or attributes, which are similarly abstract but owing to their intensional nature less clearly individuated, and so definitely no improvement. Russell's sloppy usage of the phrase "propositional function," which according to Quine confuses use and mention and blurs the distinction between predicates and attributes, obscures this fact. Second-order logic is "set theory in sheep's clothing" - unless it is property theory in sheep's clothing, which would be worse. In "On What There Is," Quine compares the three modern schools of thought on philosophy of mathematics, logicism and intuitionism and formalism, to the supposed three medieval schools of thought on the problem of universals, platonism and conceptualism and nominalism: The Russell-Whitehead "logicist" reduction, for all its importance as the first demonstration that a reduction of all of mathematics to a common basis is feasible, is just as "platonistic" as, and in principle really no different from, Zermelo's or Frankel's codification of mathematics within orthodox axiomatic set theory ZF, or Quine's own efforts in the direction of codification within his rather ad hoc heterodox set theory NF. 
It seems from all this that a crucial mark of the genuinely logical for Quine is a lack of existential implications, and that it is on account of its having such implications that mathematics is placed by Quine outside the scope of pure logic. Quine is not fanatical about freedom from existential implications, however, at least not in the manner of advocates of so-called free logic. He is prepared to admit classical logic's conventional assumption that the domain of quantification is nonempty, so that anything of the form $\forall x F x \rightarrow \exists x F x$ counts as a logical truth, if only because it is not a very difficult matter to work out separately the logic of the empty domain. In all this there is only a demand for clarity of vision, for acknowledgment of the presence of existential implications where they are present - and likewise of the absence of existential implications where they are absent: One should not imagine that merely by calling a fire engine red one is implying the existence of a property or attribute of redness.

The simplicity of what Quine is calling for is masked, however, by his use of the fancy term "ontological" and the fancier "ontological commitment" and fanciest of all "criterion of ontological commitment," terminology that seems to have been adopted for no better reason than to needle Carnap, who hated the word "ontologisch" as much as (and perhaps because) Heidegger loved it. The jargon has given rise to the confused 
notion that an ontological commitment is something much grander and graver than a mere existential implication, and to a literature that Quine would surely have deplored, debating whether this or that existential implication does or does not involve a genuine ontological commitment.

$\S 4$ Abstract Objects: Nominalism and the "Indispensability Argument" Rather abruptly there appears in the mid-1940s in Quine's lecturing and writing something going far beyond a mere demand for clarity in matters of what he insists on calling "ontology." The famous 1947 joint paper with Goodman in the Journal of Symbolic Logic opens with the flat announcement "We are nominalists." Suddenly there is a much more serious objection to logicism than the terminological one that it has misdescribed as "logic" what is really set theory: an objection to set theory as such, on account of the "abstractness" of its objects. For rejection of abstract entities is what Quine takes nominalism to consist in, not that he is ever very explicit about just what constitutes the distinction between abstract and concrete.

The claim that mathematics is not logic is replaced by the claim that mathematics is not legitimate, and needs to be replaced by something much more radically different than anything Brouwer or his intuitionists ever proposed. This demand for replacement occurs not only abruptly, but also 
without much in the way of motivating discussion. No motivation at all for undertaking such a revolution is offered in the joint paper with Goodman, where nominalism is simply described at the outset as "a philosophical intuition that cannot be justified by appeal to anything more ultimate." To judge from Paolo Mancosu's published accounts of his examination of the evidence, little more is said about motivation in the material from the Quine Nachla $\beta$ that has been uncovered so far.

In present-day discussions of nominalism in philosophy of mathematics, lack of causal powers is generally taken to be the note of the abstract, and the apparent impossibility of making mathematics conform to a causal theory of knowledge - the "Benacerraf problem," as it is called, after the discussion in Benacerraf's famous paper "Mathematical Truth" is taken as the chief motivation for nominalism. But there is nothing at all like this in Quine. For the concept of cause plays no role whatsoever in Quine's philosophy. Presumably he, like Russell before him, regards causality as a pre-scientific concept, alien to the standpoint of modern physics. Quine's nominalism seems something more like an assthetic principle, with not much more than "a taste for desert landscapes" behind it. His occasional gestures towards "Occam's Razor" as a supposed principle of scientific methodology seem more or less an afterthought. 
Subsequent professed nominalists have been willing to press into service in the nominalistic reconstruction or reconstrual of mathematical theories or mathematically-formulated scientific theories such devices as modal logic, substitutional quantification, and strong assumptions about the existence of regions of spacetime as entities over and above any material contents they may possess. Modal logic and substitutional quantification Quine emphatically rejects, as I have already indicated. Neither form of logic, according to Quine, can help reduce ontological commitments, since either, or indeed any departure from classical extensional first-order logic, simply "obstructs ontological comparison," which can only be made between theories formulated on a common logical basis. Quine is also unwilling to assume space infinite in either extent or divisibility, nor will he admit immaterial geometric entities. With such self-imposed restrictions, it is no surprise that Quine does not succeed in reconstructing much of orthodox mathematics.

Yet Quine is never tempted by the cheap and easy option of adopting a mere instrumentalist stance, a stance recognizing that orthodox, mathematically-formulated scientific theories are useful, but classifying them as useful fictions on account of their ontological commitments to abstract mathematical entities. The tenability of nominalism for Quine 
stands or falls with the feasibility or infeasibility of nominalistic reconstruction of the mathematics needed for scientific applications, and they very limited success of his own efforts in that direction with Goodman eventually led Quine to conclude that nominalism must be abandoned.

It is not entirely clear just when Quine's renunciation of nominalism occurred. By 1953, when lising the joint paper with Goodman in the bibliography of his From a Logical Point of View, Quine added to the listing a note about the opening sentence "We are nominalists" of that paper, to the effect that he would now prefer that sentence to be taken as a "hypothetical statement of conditions for the construction at hand," rather than an expression of his actual opinion. Later he was to claim that one would misunderstand his 1948 paper "On What There Is" if one tried to read into it the nominalism of the 1947 paper with Goodman. But as late as 1956 Goodman can be found describing Quine's "defection" from nominalism as "still somewhat tentative."

In connection with Quine's post-nominalist views it has become customary to speak of "Quine's indispensability argument" — or "the Quine-Putnam indispensability argument," by way of acknowledgment of the appearance of at least superficially similar thinking in Hilary Putnam's Philosophy of Logic. There is no canonical source for such an argument in 
Quine's writings, comparable to Putnam's little book, but merely scattered passages here and there in Quine's papers from the 1950s or 1960s onward. Attempts in the literature to turn Quine's remarks into an argument with numbered premises, intermediate steps, and conclusion generally drift rather far from any Quinean texts.

In particular, one does not find in Quine's writings the phrase, so often met with in reconstructions, "our best scientific theories," let alone the premise "We ought to believe in the entities posited in our best scientific theories." The phrase is, in fact, fatally ambiguous, and exploiting the ambiguity makes the premise as stated very easy to attack. The ambiguity in the phrase "our best scientific theories" is that it may refer either to (i) an idealization that is useful in practice, or to (ii) a real belief or expert opinion.

For instance, in one sense "our best scientific theory" of gravitation is (i) Einstein's general relativity; in another sense "our best scientific theory" of gravitation is (ii) the judgment that Einstein's general relativity needs a quantum correction that no one at present quite knows how to give it, but that the error involved is small enough to leave Einstein's theory safely in, say, application to events in the solar system. Here (i) is the best fullydeveloped, worked-out theory, while (ii) is the actual opinion of the bestinformed experts (or so I take it to be). 
The problem with reconstructions of Quine's thought that invoke a premise "We ought to be believe in the entities posited by our best scientific theories," is that they invite the objection "Why should we take seriously the existential implications of a theory like (i), given that according to expert opinion it is not true?" The existential implications we need to take seriously, on Quine's view, are not those of (i) but rather those of (ii). It is the mathematics presupposed in the real expert opinion that directly matters, and this does include theorems on the existence of solutions with various special properties to the field equations of general relativity, even though the real expert opinion is that general relativity is only an approximation to something more complicated that remains to be developed.

The phrase "indispensability argument" does not appear in Quine's writings, either. This phrase, however, in contrast to the phrase "our best scientific theories," is not misleading. For it does really seem to be Quine's view that only the indispensable necessity of positing mathematical entities in science can justify belief in them; the mere fact that such posits are a customary convenience is not enough for Quine, as it might be for another philosopher. There is a bias against mathematical entities in Quine's thinking, and he never doubts that it would be better to get rid of them if only we could. Nominalism would be his position if he could make a go of 
it, as he tells us in the autobiographical statement in the 1986 Library of Living Philosophers volume on his thought.

Quine's grudging acceptance of mathematical entities extends only to the entities posited in the mathematics actually applied in science, or perhaps that plus a little bit more to round it out and make it work smoothly. Early and late Quine has been willing to let higher set theory go, not that he has ever involved himself in logicians' efforts to determine just how much is needed in the way of set-existence assumptions to get this or that standard theorem. Another philosopher might hold that it is through its empirical applications that mathematics earns a place in the circle of sciences, but that having earned that place it is as free as any other science to pursue its own ends, even where there is no immediate prospect of application. But disciplinary borders and disciplinary autonomy have never mattered much to Quine.

\section{$\S 5$ Abstract Objects: From Nominalism to Naturalism}

Carnap's "Empiricism, Semantics, and Ontology" was written at a time when Quine was still better known as a proponent than as an opponent of nominalism. For Carnap, a question such as "Do numbers exist?" could be taken in either of two ways. Taken as an "internal question," a question 
within the "linguistic framework" of number theory, the question gets an immediate and trivial affirmative answer. Taken as an "external question" it is meaningless, since it is only the adoption of the linguistic framework of number theory that gives number-talk, including number-existence questions, a meaning. The external question is at best a misleading way of raising the question whether the framework is worth adopting, and this is a question that can only be answered on ultimately pragmatic grounds.

Quine's main point in his reply, “On Carnap's Views on Ontology”, is to insist that there is only one question, and it is to be answered on ultimately pragmatic grounds. By thus refusing to divide the question, "Are there prime numbers greater than one hundred?" into the two questions "Are there such numbers according to the conventions of the linguistic framework of number theory?" and "Should we as a practical matter accept the linguistic framework of number theory?" Quine leaves himself open to Charles Parsons' complaint that he cannot explain the apparent obviousness of elementary mathematics: Even the answer to the fairly simple question of the existence of prime numbers greater than one hundred for Quine depends ultimately on whether number theory is indispensably necessary for empirical science. But Quine will not recognize two questions here, since Carnap's distinction of internal and external is for Quine just another version 
or consequence of the distinction of analytic and synthetic that he rejects. What Carnap calls "linguistic frameworks," and considers to be of a wholly different character from theoretical hypotheses formulated within a linguistic framework, are for Quine simply theoretical hypotheses of the highest level of generality, not in any fundamental way different from theoretical hypotheses of the next-to-highest level or of lower level.

It is noteworthy that in all this there is nothing whatsoever in Quine's response to Carnap to justify putting more weight on, or giving more attention to, what Quine calls “ontological” commitments as opposed to what he calls "ideological" commitments, or to justify a bias against mathematical objects, so that they can only be accepted if they are found indispensably necessary, and not merely because they are obviously convenient. The compatibility of these quasi-nominalist attitudes, which linger in Quine's post-nominalist period, with the larger themes of his philosophy is rather questionable. The tension between the lingering quasinominalism (with its unexplained ultimate source) is even more apparent if one turns from the reply to Carnap to "Posits and Reality," which seems to place everyday material bodies, subvisible particles, and mathematical abstractions absolutely on a level. 
The tension is yet more apparent still if one turns to "Epistemology Naturalized," where any critical function at all for philosophy vis-à-vis science seems to be renounced. Quine's proposal in that paper is that the philosopher should cease acting like an foreigner, evaluating science from an alien standpoint, but should become a citizen of the scientific community, and join the natives (specifically, the psychologists) in investigating how one gets from the "meager input" of sensory stimulation to the "torrential output" of scientific theory. This program seems to involve abandoning normative epistemology entirely.

According to Paul Gregory, this appearance is deceptive: Quine is tacitly presupposing a normative standard, namely, an empiricist standard, according to which theories are to be judged solely by their empirical predictions. That would mean judging them by the reliability and range of their empirical consequences, and perhaps secondarily by the efficiency with which they yield those consequences. Since Quine maintains that it is only the totality of our theory of the world as a whole that yield empirical predictions, and not individual hypotheses, it would then follow that theory of the world must be judged as a whole, with individual hypotheses being judged by how much they contribute to overall theory. 
On such a holistic empiricist view, quite as much as on the view that renounces prescriptive philosophiscal epistemology for descriptive cognitive science, there again seems to be no basis for a bias against any kind of theoretical apparatus that might prove useful, or for worrying more seriously when the apparatus involves newly posited objects (ontology) than when it merely involves new primitive predicates (ideology) applicable to objects already recognized. If the meaning of an existence assumption, even an existence assumption involving abstract objects, consists in nothing more than its contribution to the whole of scientific theory and therewith to the prediction of the course of experience, how can there be room for lingering pro-nominalism, and specifically ontological preoccupations?

Whether one adopts the obvious reading of "Epistemology Naturalized" (prescription is being abandoned for description) or accepts Gregory's suggestion (empiricist prescriptions are being presupposed), that paper seems to be in tension with certain other aspects of Quine's thought. The fact is that though Quine in "Epistemology Naturalized" pointed philosophers in a certain direction, he did not himself follow that direction to the end, or even very far. Quine never became deeply involved in interdisciplinary research with psychologists or linguists; and it does not even appear that he followed very closely the progress of those sciences 
since they turned away from behaviorism. Quine's approach to philosophy of science in general and philosophy of mathematics in particular remained one that focused on very general features, and did not much concern itself with the details of the current state either of physics or of mathematics. For one notable instance, as the prominent set theorist D. A. Martin pointed out in a review article, Quine's Set Theory and Its Logic treated the subject as if it were still an open question how to proceed in the face of the Russell paradox, though it was published at a time (1963) when the ZF axiom system had long been established as the standard (with a version or variant being adopted in the first volume of the Bourbaki series, for instance).

Quine remained more interested in the kind of tinkering with scientific theory he called "regimentation" than in the actual program of collaboration with cognitive scientists. So long as one does not think of the tinkering as improvement of the actual theories of scientists, imagining ways in which the formulation of our theory of the world could be modified is a legitimate part of naturalized epistemology, insofar as it demonstrates the conventionality or underdetermination of our theory; but I fear Quine may to the end have tended to think of his favored "regimentations" as improvements, as if the actual theories of scientists weren't good enough already. 
As Moses himself never entered the promised land, so Quine's own epistemology was never naturalized in the fullest sense. He nonetheless remains, for many contemporary philosophers who describe themselves as naturalists, an inspiring prophet of naturalism. And even for those who are unsympathetic to his naturalization proposal, the pros and cons of his indispensability argument remains a central topic in philosophy of mathematics, as his challenges to the analytic/synthetic distinction remain a central topic in philosophy of logic, and indeed in philosophy generally. 
References

Benacerraf, Paul

(1973) "Mathematical Truth," Journal of Philosophy, 70: 661-679.

Benacerraf, Paul \& Putnam, Hilary

(1983) (eds.) Philosophy of Mathematics: Selected Readings, 2nd ed., Cambridge: Cambridge University Press.

Carnap, Rudolf

(1931) “Die logizistische Grundlegung der Mathematik," Erkenntnis

2: 91-105, trans. Erna Putnam \& Gerald Massey as "The Logicist

Foundations of Mathematics," in Benacerraf \& Putnam (1983), $41-51$.

(1950) "Empiricism, Semantics, and Ontology," Revue Internationale de Philosophie 4: 20-40.

Carroll, Lewis

(1895) "What the Tortoise Said to Achilles," Mind 4: 278-280.

Goodman, Nelson

(1956) "A World of Individuals," in The Problem of Universals: A

Symposium, Notre Dame: Notre Dame University Press. 
Gregory, Paul

(2008) Quine's Naturalism: Language, Theory, and the Knowing Subject, London: Continuum.

Kripke, Saul

(1982) Wittgenstein on Rules and Private Language: An Elementary Exposition, Cambridge: Harvard University Press.

Lewis, David

(1969) Convention: A Philosophical Study, Cambridge: Harvard University Press.

Martin, D. A.

(1970) review of Quine (1963), Journal of Philosophy, 67: 111-114.

Putnam, Hilary

(1971) Philosophy of Logic, , New York: Harper.

Quine, W. V.

(1936) “Truth by Convention," in O. H. Lee (ed.), Philosophical

Essays for A. N. Whitehead, New York: Longmans, 90-124.

(1948) “On What There Is," Review of Metaphysics 2: 21-38, reprinted in Quine (1953a), 1-19.

(1951a) “On Carnap's Views on Ontology," Philosophical Studies

2: 65-72, reprinted in Quine (1966), 126-134. 
(1951b) “Two Dogmas of Empiricism,” Philosophical Review

60: 20-43, reprinted in Quine (1953a), 20-46.

(1953a) From a Logical Point of View, New York: Harper \& Row.

(1953b) "Three Grades of Modal Involvement," in Acts of the XIth

International Congress of Philosophy, Amsterdam: North Holland,

14: $65-81$.

(1960a) “Carnap on Logic Truth,” Synthese, 12: 350-374, reprinted in Quine (1966), 100-125.

(1960b) "Posits and Reality," in S. Uyeda (ed.), Basis of the

Contemporary Philosophy, Tokyo: Waseda University Press,

5: 391-400, reprinted in Quine (1966), 233-241.

(1963) Set Theory and Its Logic, Cambridge: Harvard University

Press.

(1966) The Ways of Paradox, New York: Random House.

(1969a) Ontological Relativity and Other Essays, New York:

Columbia University Press.

(1969b) Foreword to Lewis (1969), xi-xii.

(1970) Philosophy of Logic, Engelwood: Prentice-Hall.

(1971) "Epistemology Naturalized," in Acts of the XIVth International

Congress of Philosophy, 6: 87-103, reprinted in Quine (1969a), 69-90. 
(1986) “Autobiography of W. V. Quine,” in Lewis E. Hahn \& Paul A. Schilpp (eds.), The Philosophy of W. V. Quine, Library of Living Philosophers, La Salle: Open Court, 3-46.

Quine, W. V. and Goodman, Nelson (1947) "Steps toward a Constructive Nominalism," Journal of Symbolic Logic 12: 105-122.

Russell, Bertrand (1944) “My Mental Development," in Paul A. Schilpp (ed.), The Philosophy of Bertrand Russell, Library of Living Philosophers: La Salle: Open Court, 3-20. 